June 2007

\title{
Acute proximal hamstring rupture
}

Steven B. Cohen

Thomas Jefferson University

James Bradley

University of Pittsburgh

Follow this and additional works at: https://jdc.jefferson.edu/orthofp

Part of the Orthopedics Commons

Let us know how access to this document benefits you

\section{Recommended Citation}

Cohen, Steven B. and Bradley, James, "Acute proximal hamstring rupture" (2007). Department of Orthopaedic Surgery Faculty Papers. Paper 12.

https://jdc.jefferson.edu/orthofp/12

This Article is brought to you for free and open access by the Jefferson Digital Commons. The Jefferson Digital Commons is a service of Thomas Jefferson University's Center for Teaching and Learning (CTL). The Commons is a showcase for Jefferson books and journals, peer-reviewed scholarly publications, unique historical collections from the University archives, and teaching tools. The Jefferson Digital Commons allows researchers and interested readers anywhere in the world to learn about and keep up to date with Jefferson scholarship. This article has been accepted for inclusion in Department of Orthopaedic Surgery Faculty Papers by an authorized administrator of the Jefferson Digital Commons. For more information, please contact: JeffersonDigitalCommons@jefferson.edu. 


\title{
Acute Proximal Hamstring Ruptures: Review of Literature, and Treatment Options
}

\author{
Steven Cohen, $\mathrm{MD}^{1}$ and James Bradley, $\mathrm{MD}^{2}$ \\ ${ }^{1}$ Dr. Cohen is Director, Sports Medicine Research, and Assistant Professor, Department of Orthopaedic Surgery, \\ Rothman Institute Orthopaedics, Thomas Jefferson University Medical School, Philadelphia, PA. \\ ${ }^{2}$ Dr. Bradley is Clinical Associate Professor, University of Pittsburgh Medical Center, Pittsburgh, PA. \\ Reprint requests: \\ Dr. Cohen \\ Rothman Institute Orthopaedics \\ 925 Chestnut Streetl \\ Philadelphia, PA 19107-4216.
}

This is the authors' final version prior to publication in the Journal of the American Academy of Orthopaedic Surgeons, Vol 15, No 6, June 2007, 350-355. The published version is available at http://www.jaaos.org. Copyright (c) 2007 the American Academy of Orthopaedic Surgeons, all rights reserved. 


\begin{abstract}
The diagnosis and surgical treatment of proximal hamstring ruptures is becoming more common as this injury is more recognized. Nonoperative treatment of complete ruptures has led to complications such as weakness and sciatic nerve neuralgia. As a result, surgical treatment has been advocated to repair the complete rupture of the hamstring tendons from the ischial tuberosity. Surgical repair involves a transverse incision in the gluteal crease, protection of the sciatic nerve, mobilization of the ruptured tendons, and repair to the ischial tuberosity with the use of suture anchors. There have been few reports in the literature and most series have had a relatively small amount of patients. Surgical repair results in a rate of return to function and sports of 58-85\%, near normal strength, and decreased pain.
\end{abstract}

\title{
Introduction
}

As athletes of all levels have become bigger, stronger, and faster, tendon, musculotendinous junction, and muscle injuries appear to be happening with increasing frequency. Acute hamstring strains are one of the more common injuries occurring in athletes.[1] Strains are most commonly the result of an eccentric muscle contraction and most frequently occur at the musculotendinous junction. In general, mild to moderate strains respond well to conservative treatments such as rest, ice, modalities, nonsteroidal anti-inflammatory drugs (NSAIDs), gentle stretching, therapeutic exercise, and gradual return to athletic activity.

\section{Mechanism of Injury}

Proximal hamstring rupture from the ischial tuberosity although infrequently, occurs acutely both in well-trained athletes, and middle-aged patients, who sustain 
sudden hip flexion / knee extension causing hamstring contraction. This injury is rather dramatic with patients describing the sensation of being shot in the posterior thigh with subsequent difficulty ambulating.

\section{Presentation}

The gait pattern is one of a stiff legged gait as a result of avoidance of hip and knee flexion. Patients typically present with posterior thigh pain distal to the ischial tuberosity (at the location of the tendon retraction) and significant ecchymosis as a result of the hematoma from the tendon rupture. They will also complain of difficulty sitting secondary to pain at the avulsion site.

\section{Examination}

Physical examination is often difficult to determine the exact nature of the injury due to the deep location of the hamstring muscle group. A common finding is a latent large area of ecchymosis in the posterior middle and distal thigh (approximately 1 week following injury). Tenderness is usually present over the injury however palpation of a defect may or may not be easily established. It is important to test the peroneal branch of the sciatic nerve function because if there is an injury to this branch, this will cause weakness of the short head of the biceps femoris and may slow potential postoperative rehabilitation. Specifically, if there has been a neuropractic injury to the nerve, this may present as a foot drop or more subtly an eversion weakness of the ankle.

\section{Radiographs}

$\mathrm{X}$-rays may show a bony avulsion from the ischial tubersosity if present, but are commonly negative. Magnetic resonance imaging (MRI) is crucial in determining the amount of soft tissue injury, more specifically; complete versus partial rupture, number of 
tendons ruptured, and amount of retraction (Figure 1). Digital radiographs, in particular MRI, allow extremely accurate measurement of the amount retraction after tendon rupture. The digital imaging we have used is Stentor, Philips Medical System (Brisbane, CA) and is accurate to the accuracy of the DICOM tag parameters for pixel spacing. The iSite PACS application automatically adjusts to physical data points, so there is no inaccuracy on interpolated data.

\section{Treatment Algorithm}

The algorithm we generally follow is; a single tendon avulsion is treated nonoperatively despite retraction up to $1-2 \mathrm{~cm}$. In our experience athletes are able to return to high level sports (professional football) approximately 6 weeks after injury. The ruptured single tendon scars to the intact tendons and allows return to full strength. An acute three tendon (semitendinosus, semimembranosus, and long head of biceps femoris) tear typically has a significant amount of retraction of up to $5 \mathrm{~cm}$ or more. This is treated with surgical repair.

A more difficult decision is how to treat a two of the three tendon rupture. Even though MRI findings may show avulsion of 2 tendons, the third tendon may have a significant injury associated with the musculotendinous junction (MTJ) and may be attenuated. We recommend repair in younger $(<50$ years $)$ more active individuals especially those still participating in athletics with retraction of the ruptured tendons of 2 $\mathrm{cm}$ or more. There are no specific guidelines in the literature on the amount of retraction that should be treated surgically. Retraction of $2 \mathrm{~cm}$ or greater has been a cut off for surgical treatment in our experience. When retraction of the 2 tendons reaches $2 \mathrm{~cm}$ this has been indicative of an injury to the third "attached" tendon usually at the MTJ or 
muscle belly in our patients that may not be apparent on MRI. Failure to address this surgically may result in residual pain, weakness, and hamstring dysfunction.

\section{Overview}

The frequency of these injuries appears to be increasing both clinically and by report in the literature, as more middle-aged patients remain more active and the recognition and potential for treatment has become better established. Proper treatment includes a thorough evaluation and discussion with the patient regarding treatment options. Many of the series reported in the literature of proximal hamstring repair contain few patients, with the largest series of acute repairs consisting of 7 patients [2]. Additionally, the technique for surgical repair has not been well established.

\section{Review of Literature}

There have been few reports in the literature on the surgical treatment of proximal hamstring injuries. The small numbers of published studies contain both acute and chronic tears and include a relatively small number of patients.[2-7] The findings in these studies are summarized in table 1.

Klingele and Sallay reported on the primary surgical repair of complete proximal hamstring ruptures in 11 patients [2]. The average age of the patients was 41.5 years and the mechanism of injury varied. MRI was used to confirm complete injuries in all patients. Surgery was recommended for acute complete rupture in active patients with functional disability, and in chronic cases with pain caused by sciatic nerve compression and inability to return to vigorous activity.

Chakravarthy et al reported on the surgical treatment in 4 cases of complete proximal hamstring tendon ruptures in water skiers and bull riders [3]. Two of the three 
patients initially treated conservatively suffered from sciatic neuralgia, and all 4 patients had significant knee flexion weakness and thigh pain.

Cross et al reported on the surgical repair of chronic complete rupture in nine adult patients.[4] They felt that the acute diagnosis of complete ruptures was difficult due to the minimal clinical awareness. Hamstring strength and endurance were an average of $60 \%$ and $57 \%$ respectively at an average of 48 months although only 7 of the nine patients were available for testing.

Brucker and Imhoff described the functional assessment (by performing Cybex dynamometer isokinetic testing measuring maximum hamstring and quadriceps torque and peak torque ratio of hamstring to quadriceps at a velocity of 60 degrees per second) after repair of acute and chronic hamstring repairs in 8 patients.[5] MRI was used to confirm the diagnosis in all cases. Return to sports activities was allowed after 6-8 months. At 20 months follow-up, 50\% complained of incisional pain and discomfort with one patient requiring an additional surgery after pullout of a metal suture anchor.

Sallay et al described the results of 12 patients with water skiing-related hamstring injuries with an average time from injury to initial evaluation of 5.6 months (range: 6 weeks to 18 years).[6] The mechanism was commonly an eccentric contraction while attempting to get up from the submerged position in novice skiers and injury from a fall in expert skiers. Initial treatment was non-operative and half of the patients had MRI or CT scans to assess the injury. Five MRI and one CT scan were used to evaluate the exact site and extent of the hamstring tear. Five patients ultimately required delayed surgical repair due to persistent functional limitations. This study confirmed the functional deficit associated with complete proximal hamstring tears. 
Orava and Kujala treated 8 patients with surgical repair who had complete rupture (all 3 tendons) of the hamstrings from the ischial tuberosity.[7] The mean age of their patients was 40 years and the injury was the result of a sudden forceful flexion of the hip when the knee was extended, and occurred during athletics. In 7 of the 8 cases ultrasound was used to confirm complete tendon rupture. The results with regard to function and strength were improved in the 5 patients who underwent repair less than 2 months following the injury compared to the 3 chronic repairs. Acute repair allows easier re-approximation of the tendon to its insertion on the ischial tuberosity. In addition, the authors recommend nonoperative treatment for isolated biceps femoris ruptures as little functional disability results from this injury. Consequently, they recommended prompt surgery to accomplish a primary repair of the tendons to its origin.

In summary, complete rupture of the proximal hamstrings is an uncommon injury that if not treated acutely leads to weakness, pain, and potential for sciatic neuralgia, which is similar to hamstring syndrome as described below. Reports in the literature have small series of patients evaluated retrospectively with a variety of surgical techniques and timing to surgery. The consensus in the literature however is an improved result is obtained with earlier treatment of complete proximal hamstring ruptures.

\section{Nonoperative Treatment}

Nonoperative is recommended in the case of single tendon rupture regardless of retraction amount and multiple tendon tear with minimal retraction $(<2 \mathrm{~cm})$. Treatment consists of rest, ice, modalities, NSAIDs, gentle stretching, therapeutic exercise, and gradual return to athletic activity, over approximately 4 to 6 weeks. 
Nonoperative treatment of significant proximal hamstring ruptures (two or more tendons) may result in knee flexion and mild hip extension weakness, sitting difficulty, deformity, and the potential development of symptoms similar to hamstring syndrome as the tendons scar down to the sciatic nerve. Hamstring syndrome as described by Puranen and Orava consists of local posterior buttock pain and discomfort over the ischial tubersosity [8]. In most cases the pain begins without specific trauma and characteristically is painful during sitting. In addition, the pain may worsen with stretching and during exercise (sprinting, hurdling, or kicking). In some cases of persistent hamstring syndrome, surgical release and sciatic nerve decompression are necessary to relieve the symptoms, which was successful in 52 of 59 patients $(88 \%)$ in their series [8].

Acute repair allows easier mobilization of the tendons (usually a single tendon wad comprising all three tendons) and repair to the ischial tuberosity. Chronic rupture repair yields less consistent results with the potential issue of scarring to the sciatic nerve possibly requiring concomitant dissection of the nerve from the avulsed tendons followed by sciatic neurolysis.

\section{Surgical Treatment / Technique}

The patient is placed in the prone position and a transverse incision is made in the gluteal crease directly inferior to the ischial tuberosity. We prefer a transverse incision in the gluteal crease for its cosmesis and accessibility to the avulsed tendons, as opposed to a longitudinal incision. If necessary, the transverse incision may be extended to provide greater access for retrieval of any retracted tendons. The incision is taken down to the gluteal fascia taking care to avoid the posterior femoral cutaneous nerve. A transverse 
incision is made in the gluteal fascia. The gluteus maximus muscle is elevated and retracted superiorly. This allows exposure to the hamstring fascia. A longitudinal incision is made in the hamstring fascia. Typically an additional layer of scar lies over the ruptured coalescence of the hamstring tendons, and it will appear that tendons are not ruptured, but this layer must be incised to locate the tendons. After this layer is entered, this exposes the large amount of hematoma, which is present from the tendon rupture. The sciatic nerve can be palpated and protected by lateral retraction of the group of tendons. After the tendons are identified, the scar on the ends of the tendon is removed and the tendon edges are abraded to normal tendon (Figure 2). It is crucial to remove the scar but not perform excessive removal, which can leave the tendon length shortened. The tendons are mobilized and tagged with a heavy suture. Next, the ischial tuberosity is identified and the lateral aspect is cleared off with a periosteal elevator. It is important to reattach the tendons to their anatomic origin, which is on the lateral aspect of the tuberosity. The anatomical origin of the semimembranosus is the most lateral and the semitendinosus and long head of the biceps femoris are medial to the origin of the semimembranosus arising from a common aponeurosis [8] (Figure 3). The tubersosity is denuded to provide for bony healing using curettes. The tendons are repaired to bone with the use of suture anchors. We prefer the bioabsorbable anchors with abrasion resistant suture due to the strength of the suture and lower knot profile. The anchors are placed in the configuration of an " $X$ " using a total of five anchors (Figure 4). The sutures are passed through the tendons using horizontal mattress sutures from inferior to superior and tied down from superior to inferior with the knee flexed 30 degrees. We have not had success using Bunnell, modified Kessler, or modified Mason-Allen stitches 
because those stitches tend to bunch up the tendon at the bony interface on the ishcial tuberosity. The fascia is closed and the wound is closed in layers. The affected leg is then placed in a custom fitted hip orthosis, which restricts hip flexion from 15 to 30 degrees (figure 5). Limiting hip motion limits the stress at the re-attachment site. The patient then ambulates on crutches toe-touch weight bearing.

\section{Postoperative rehabilitation:}

The rehabilitation protocol described below was used for each of the patients in our series. This allowed for consistency regardless of findings at surgery or "tension" of the repair. The first phase of rehabilitation consists of toe-touch weight bearing for 10-14 days with advancement to $25 \%$ weight bearing for the next three weeks. This allowed slight hip and knee flexion, taking care to prevent any stress on the tendon repair. Passive range of motion (PROM) of the knee and hip is begun at week 2 and gentle active ROM is initiated by week 4 . The brace is discontinued by week 6 .

The second phase starts with full weight bearing at week 5 and normal gait training. PROM and AROM are progressed as well as aqua therapy. Isotonic exercises are begun within a limited range of motion avoiding the terminal ranges of motion. Core pelvic strength training and closed chain exercises are also initiated. At 8 weeks after surgery, isotonic strength training is progressed and dynamic training is advanced. An isometric strength evaluation at 60 degrees of knee flexion is performed at 10 weeks.

The final phase of rehabilitation consists of the initiation of dry land jogging after 10 weeks. A full isokinetic evaluation is performed at 60 degrees, 120 degrees, and 180 degrees/second and compared to the nonoperative side. This provides objective evidence of strength deficits for patients and therapists, and allows specific milestones for return to 
sport. Sports specific activities are continued and return to sporting activity is allowed when isokinetic testing is $80 \%$ of the unaffected side, similar to return for patients after ACL reconstruction [9]. This typically occurs between 6 and 9 months.

The results of our current series of acute hamstring repairs include 7 patients with 8 hamstring repairs (one bilateral) with an average patient age of 42.7 years (range: 2458). All injuries occurred via an eccentric contraction of the hamstrings. Subjective complaints consisted of pain, weakness, and difficulty sitting. All repairs were performed with the surgical technique described above at an average of 5.7 days after injury. All patients underwent preoperative MRI. The average time to return to function / athletics was 8.5 months including one patients' return to professional football. Five patients who underwent Cybex testing revealed greater than $80 \%$ strength compared to the uninjured side at an average of 5.8 months. All patients were satisfied with the procedure at latest follow-up of greater than 6 months and 6 of 7 returned to preoperative sport or activity level.

\section{Conclusions}

Hamstring strains are common injuries, however complete proximal hamstring ruptures occur with less frequency. There must be awareness for this injury as well as a thorough physical examination supplemented by the use of MRI to avoid missing the diagnosis. Acute surgical treatment of proximal hamstring avulsions allows anatomic repair and lessons symptoms similar to hamstring syndrome while allowing the majority of patients functional return to activities including high-level athletics. 


\section{References}

1. Clanton TO, Coupe KJ. Hamstring strains in athletes: Diagnosis and treatment. JAAOS 1998;6:237-248.

2. Klingele KE, Sallay PI. Surgical repair of complete proximal hamstring tendon rupture. Am J Sports Med 2002;30:742-747.

3. Chakravarthy J, Ramisetty N, Pimpalnerkar A, Mohtadi N. Surgical repair of complete proximal hamstring ruptures in water skiers and bull riders: A report of four cases and review of the literature. Br J Sports Med 2005;39:569-572.

4. Cross MJ, Vendersluis R, Wood D, Banff M. Surgical repair of chronic complete hamstring tendon ruptures in the adult patient. Am J Sports Med 1998;26:785-788.

5. Brucker PU, Imhoff AB. Functional assessment after acute and chronic complete ruptures of the proximal hamstring tendons. Knee Surg Sports Traumatol Arthrose 2005;13:411-418.

6. Sallay PI, Friedman RI, Coogan PG, Garrett WE. Hamstring muscle injuries among water skiers. Functional outcome and prevention. Am J Sports Med 1996;24:130-136.

7. Orava S, Kujala UM. Rupture of the ischial origin of the hamstring muscles. Am J Sports Med 1995;23:702-705.

8. Puranen J, Orava S. Hamstring syndrome: A new diagnosis of gluteal sciatic pain. Am J Sports Med 1988;16:517-521.

9. Shelbourne KD, Nitz P. Accelerated rehabilitation after anterior cruciate ligament reconstruction. Am J Sports Med 1990;18:292-299. 


\section{Figures}

Figure 1: MRI example of an acute complete proximal hamstring rupture from the ischial tubersosity. A) Coronal T2 weighted image B) Axial T2 weighted image

A.

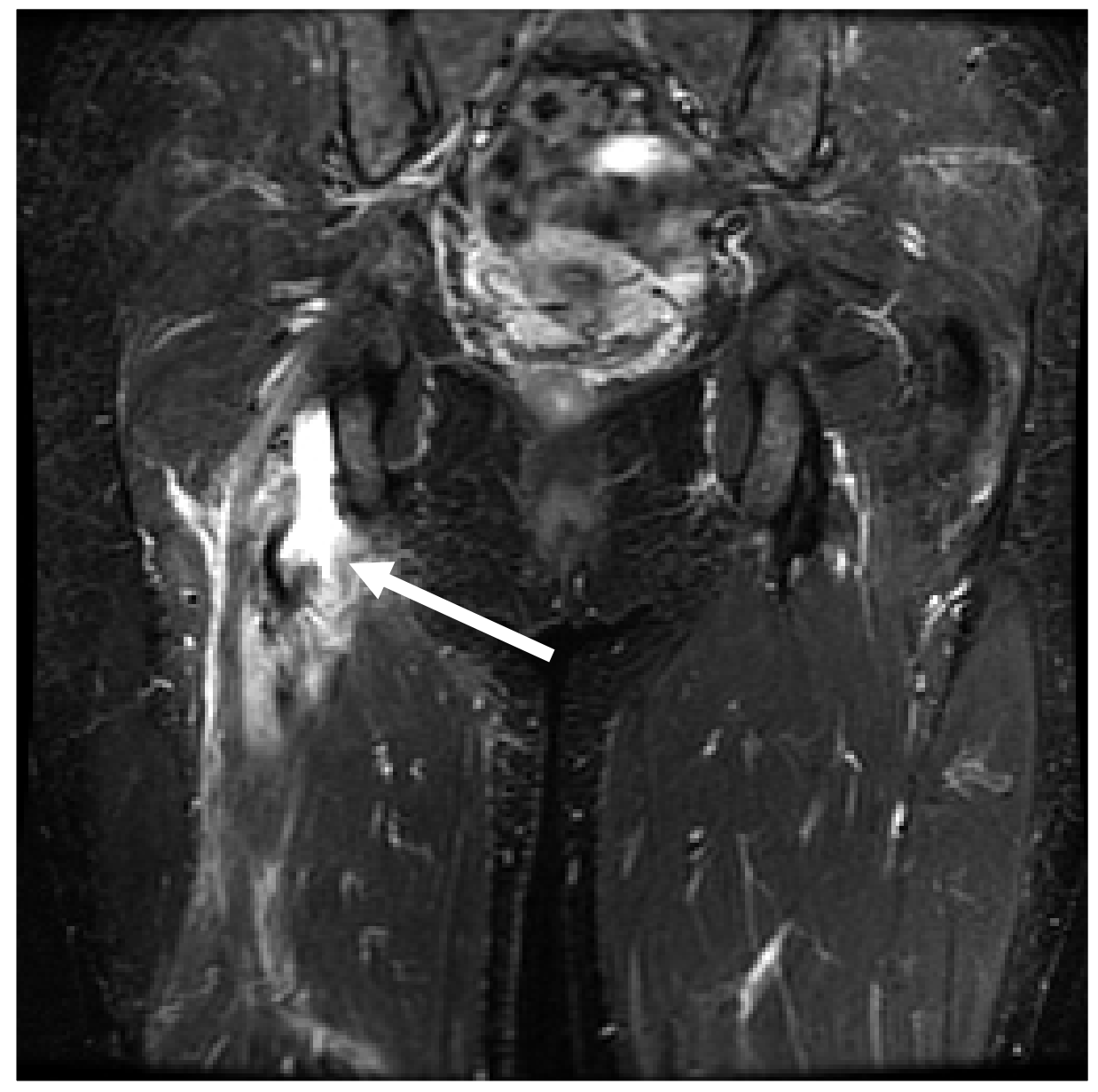


B.

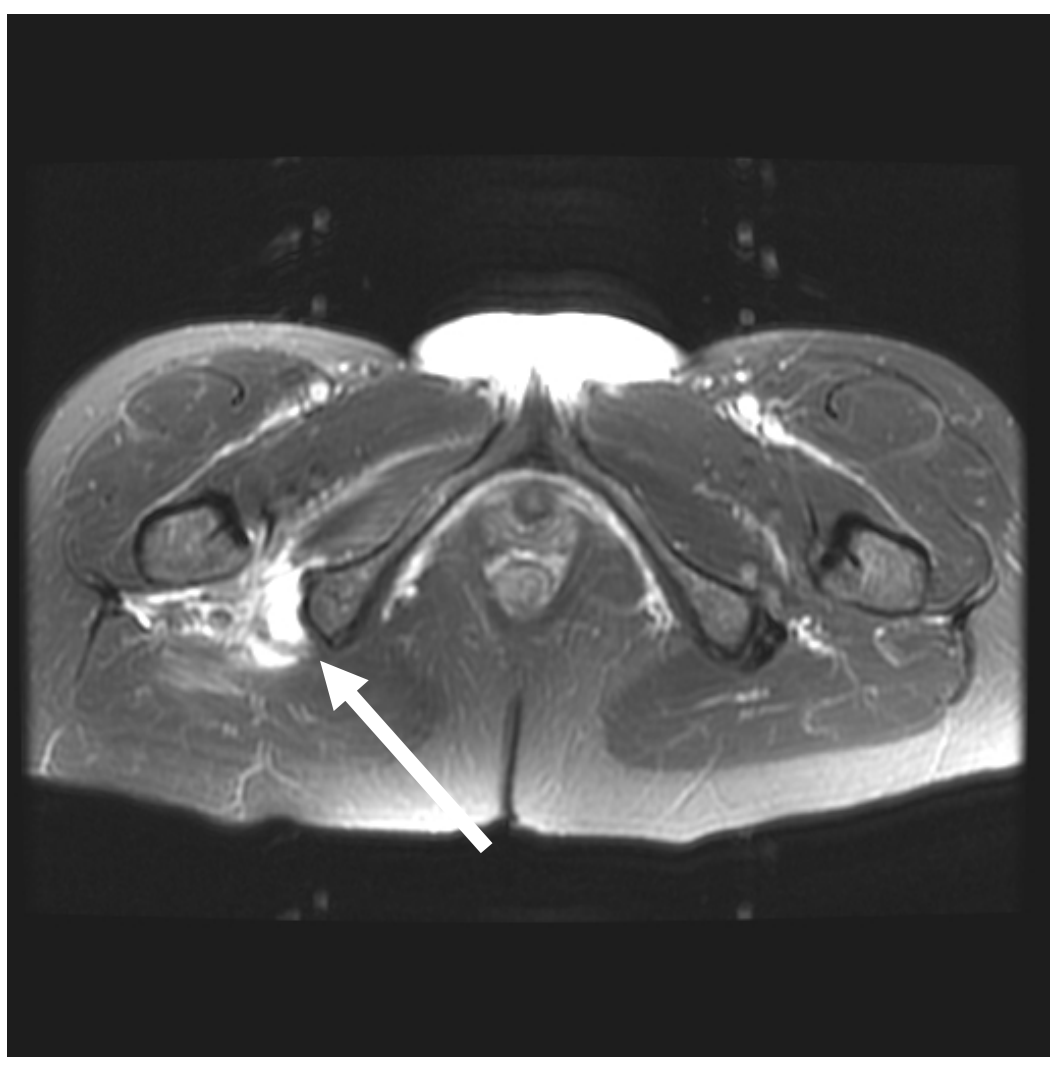


Figure 2: Appearance of the proximal hamstring tendons with retraction after rupture from the insertion on the lateral aspect of the ischial tuberosity.

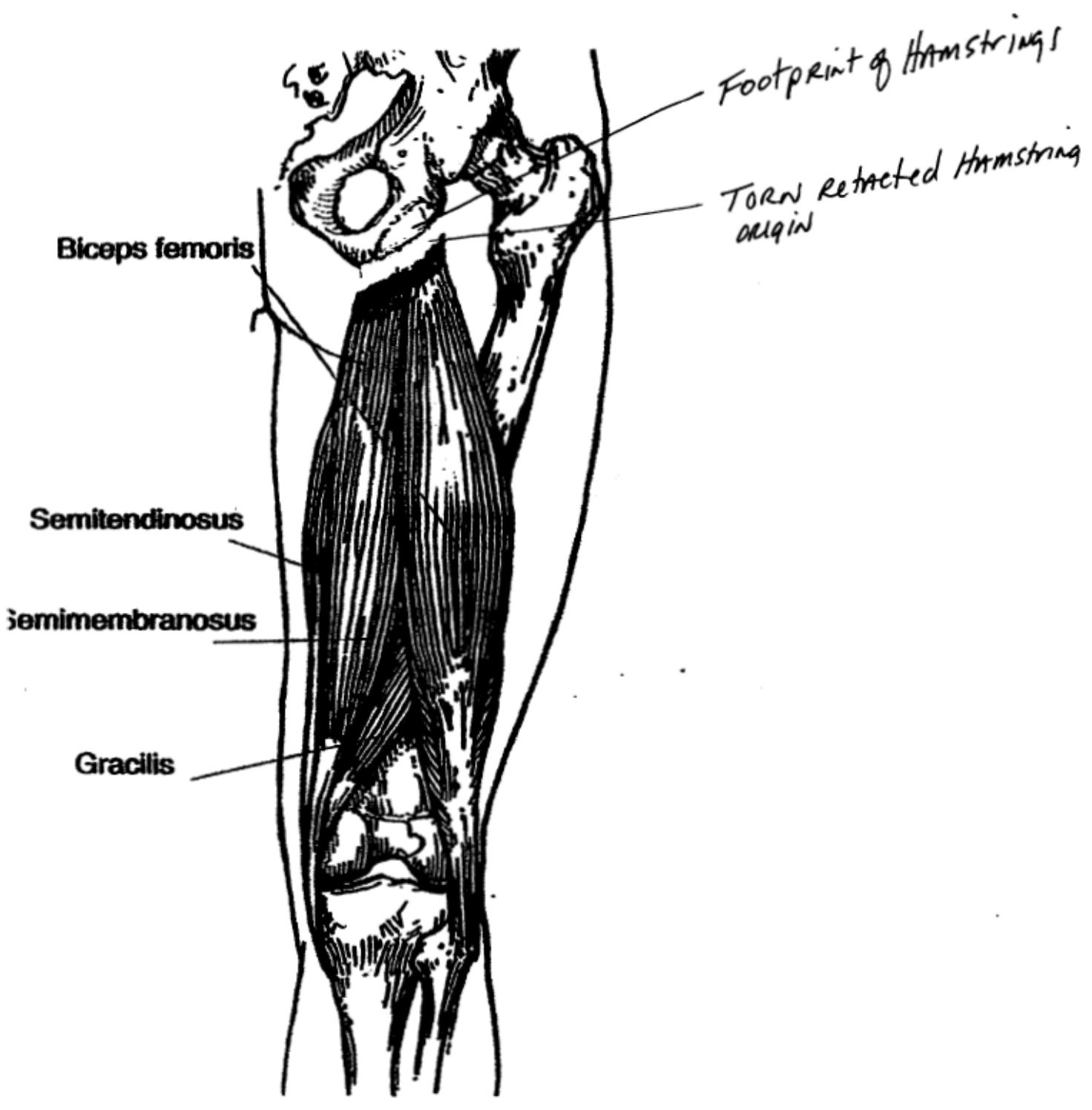


Figure 3: Anatomy of the hamstring muscles and their origin on the ischial tuberosity.
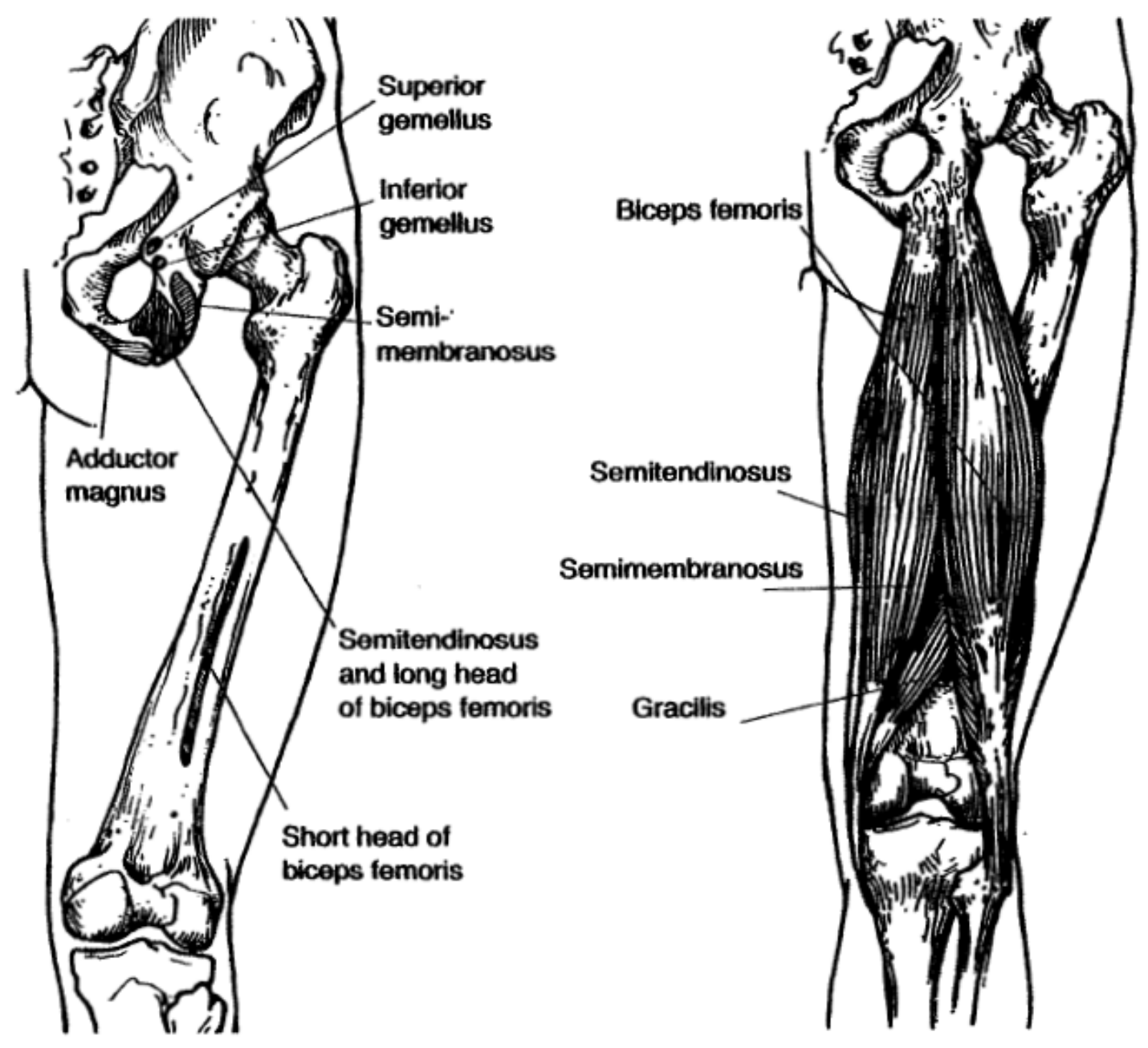
Figure 4: Depiction of the proximal hamstring repair on the ischial tuberosity with the use of 5 suture anchors in the "X" configuration.

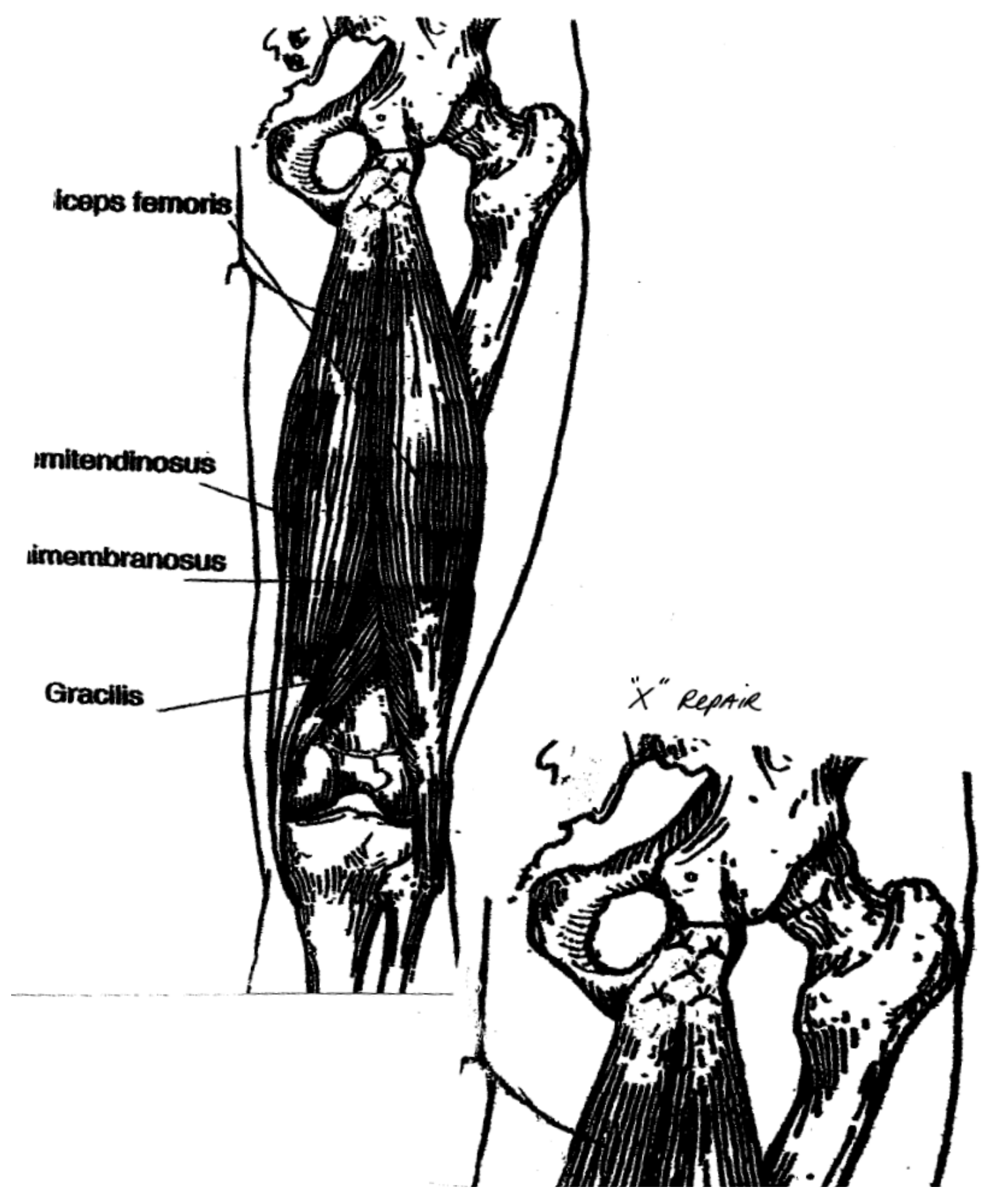


Figure 5: Post-operative brace worn following proximal hamstring repair.

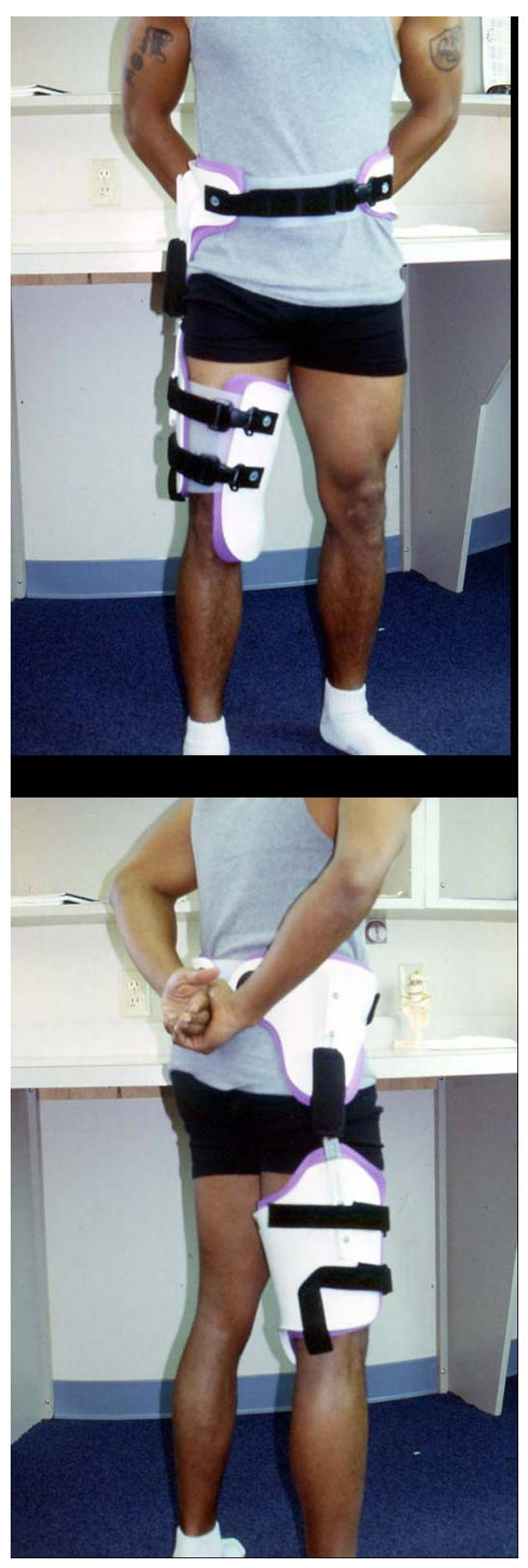


Table 1: Summary of studies on proximal hamstring repair

\begin{tabular}{|c|c|c|c|c|}
\hline Study & \# of Patients & $\begin{array}{l}\text { Method of } \\
\text { Repair }\end{array}$ & Follow-Up & Outcome \\
\hline $\begin{array}{l}\text { Klingele \& } \\
\text { Sallay }\end{array}$ & 11 (7 acute) & $\begin{array}{l}\text { Longitudinal } \\
\text { incision with 2-3 } \\
\text { anchors }\end{array}$ & 34 months & $\begin{array}{l}91 \% \text { satisfaction } \\
73 \% \text { pain free or } \\
\text { mild pain with } \\
\text { activity } 43 \% \\
\text { moderate } \\
\text { limitations } \\
85 \% \text { return of } \\
\text { strength with } \\
\text { Cybex testing }\end{array}$ \\
\hline $\begin{array}{l}\text { Chakravarthy et } \\
\text { al }\end{array}$ & 4 (1 acute) & $\begin{array}{l}\text { Longitudinal } \\
\text { incision with } \\
\text { metal anchors or } \\
\text { primary repair }\end{array}$ & 12 months & $\begin{array}{l}75 \% \text { returned to } \\
\text { sport } \\
\text { all regained } \\
\text { strength and near } \\
\text { normal motion } \\
\text { all sciatic nerve } \\
\text { symptoms } \\
\text { resolved }\end{array}$ \\
\hline Cross et al & 9 (0 acute) & $\begin{array}{l}\text { Longitudinal } \\
\text { incision with and } \\
\text { without anchors }\end{array}$ & 48 months & $\begin{array}{l}\text { Hamstring } \\
\text { strength } 60 \% \text { at } \\
\text { follow-up }\end{array}$ \\
\hline $\begin{array}{l}\text { Brucker \& } \\
\text { Imhoff }\end{array}$ & 8 (6 acute) & $\begin{array}{l}\text { Repair with } \\
\text { average of } 3.5 \\
\text { anchors }\end{array}$ & 20 months & $\begin{array}{l}75 \% \text { returned to } \\
\text { sport, } 10 \% \\
\text { deficit on } \\
\text { isokinetic muscle } \\
\text { testing }\end{array}$ \\
\hline Sallay et al & 12 ( 0 acute) & $\begin{array}{l}\text { Not specified ( } 5 \\
\text { of } 12 \text { required } \\
\text { late surgical } \\
\text { repair) }\end{array}$ & $\begin{array}{l}7.45 \text { years } \\
\text { (range: } 6 \text { mo - } \\
18 \text { years) }\end{array}$ & $\begin{array}{l}58 \% \text { returned to } \\
\text { sports (all partial } \\
\text { tears) } \\
42 \% \text { unable to } \\
\text { return to sports a } \\
\text { same level (all } \\
\text { complete tears) }\end{array}$ \\
\hline Orava \& Kujala & 8 (5 acute) & $\begin{array}{l}\text { Primary repair to } \\
\text { bone through } \\
\text { drill holes with / } \\
\text { without } \\
\text { augmentation }\end{array}$ & 5.7 years & $\begin{array}{l}62 \% \text { good } \\
\text { outcome }\end{array}$ \\
\hline
\end{tabular}

